\title{
Effect of dexmedetomidine on hemodynamic changes and inflammatory responses in patients undergoing off-pump coronary-artery bypass grafting
}

\author{
WENQIAN ZHAI ${ }^{1,2 *}$, LIEMING YANG $^{3 *}$, PENG SUN $^{2}$, YUNFEI LI $^{1}$, JIANGE HAN $^{2}$ and GUOLIN WANG ${ }^{4}$ \\ ${ }^{1}$ Tianjin Medical University, Tianjin 300070; ${ }^{2}$ Department of Anesthesiology, Tianjin Chest Hospital, \\ Tianjin 300222; Departments of ${ }^{3}$ Cardiovascular Surgery and ${ }^{4}$ Anesthesiology, \\ General Hospital of Tianjin Medical University, Tianjin 300052, P.R. China
}

Received December 3, 2019; Accepted July 7, 2020

DOI: $10.3892 /$ etm.2020.9380

\begin{abstract}
The aim of the present study was to determine the effect of dexmedetomidine on hemodynamic changes and inflammatory responses in patients undergoing off-pump coronary artery bypass grafting (OPCABG). A total of 300 patients about to receive OPCABG were randomized evenly into the control group $(n=116)$ and study group $(n=123)$. Intravenous dexmedetomidine pump infusion was administered to patients in the study group at a rate of $0.4 \mu \mathrm{g} \cdot \mathrm{kg}^{-1} \cdot \mathrm{h}^{-1}$. The control group received physiological saline at the same infusion speed. Changes in hemodynamic parameters and inflammatory indices were compared between the two groups. Hemodynamic parameters, such as the heart rate and mean arterial pressure, were lower in patients from the study group, compared with that in the control group (both $\mathrm{P}<0.05$ ). The levels of pro-inflammatory factors, such as interleukin (IL)-6, tumor necrosis factor- $\alpha$ and C-reactive protein, were also reduced in the study group $(\mathrm{P}<0.05)$. The observed levels of IL-10 were lower in the control group compared with that in the study group, although a statistically significant difference was not achieved. Thus, the administration of dexmedetomidine in patients undergoing OPCABG stabilized hemodynamics and reduced inflammation. The present study was registered at the Chinese Clinical Trial Registry, under the trial registration number ChiCTR-OOC-15005978 (2015).
\end{abstract}

Correspondence to: Dr Guolin Wang, Department of Anesthesiology, General Hospital of Tianjin Medical University, 154 Anshan Road, Heping, Tianjin 300052, P.R. China

E-mail: 103844013@qq.com

*Contributed equally

Key words: dexmedetomidine, off-pump coronary-artery bypass grafting, hemodynamic changes, inflammatory responses

\section{Introduction}

Coronary artery disease (CAD) is a major cardiovascular disease that affects the global population. CAD is a major cause of death in developed and developing countries (1). With advances in medical technology, effective medication and interventional therapy, off-pump coronary artery bypass grafting (OPCABG) has become increasingly available for patients with coronary heart disease in Asia. OPCABG can be achieved with a low mortality and a good medium to long term survival. OPCABG is associated with fewer post-operative complications and comparable late coronary interventions (2). However, in the majority of patients who suffer from severe myocardial ischemia, surgery can activate the sympathetic nerves, triggering the release of catecholamine. This subsequently causes adverse cardiovascular reactions, such as elevated blood pressure and increased heart rate, directly affecting the prognosis of patients $(3,4)$. Therefore, anesthesiologists should select appropriate anesthetic drugs to create safe and comfortable conditions for surgery, reduce the post-operative inflammatory response and have little impact on the hemodynamic indices.

Dexmedetomidine is a novel and highly selective $\alpha-2$ adrenergic receptor agonist, with an $\alpha 2: \alpha 1$ receptor affinity of 1620:1 (5). It has analgesic, sedative and anxiolytic properties, with a mild inhibitory effect on respiratory function (6-8). Dexmedetomidine is used as a sedative in critical illness and may serve anti-inflammatory effects (9). Hence the present study investigated the effects of dexmedetomidine on the hemodynamics and inflammatory response of 239 patients undergoing OPCABG surgery.

\section{Materials and methods}

Patient selection. A total number of 300 patients undergoing OPCABG, aged 55-75 years old, weighing 55-85 kg and with American Society of Anesthesiology II-III (10), were included in the present study regardless of their sex and education level (Table I). Patients with neurological/mental health conditions or organs (including brain, lung, liver and kidney) dysfunction were excluded. All subjects were well-informed and provided 
written informed consent before accepting anesthesia. The present study was approved by The Ethics Committee of Tianjin Chest Hospital (approval no. 2012KY-001-01) and was registered at the Chinese Clinical Trial Registry, under trial registration number ChiCTR-OOC-15005978 (2015).

Randomization and study blinding. Patients were randomly assigned into the control group (group C), in which no intraoperative intravenous pump infusion of dexmedetomidine was used. In the dexmedetomidine group (group D), dexmedetomidine was infused at a rate of $0.4 \mu \mathrm{g} \cdot \mathrm{kg}^{-1} \cdot \mathrm{h}^{-1}$, starting from endotracheal intubation to the end of the surgery. The dosage and ratio of dexmedetomidine were calculated according to the recommended dosage in combination with the body weight of the patient. Based on the findings from retrospective studies $(11,12)$, a total of 127 patients were required in each group with an $\alpha$-level of 0.05 and power of 0.8 . Assuming a $20 \%$ withdrawal rate during the course of the clinical trial, including study design deviation and consent withdrawal, 150 patients were enrolled into each group.

During the study period, 300 patients were screened, and 279 of these met the inclusion criteria (including undergoing OPCABG, an age of 55-75 years old, weighing 55-85 kg and with an American Society of Anesthesiology score of II-III), leaving 135 patients in group C and 144 patients in group D. Among the enrolled patients, 40 were excluded due to the following reasons: i) Intraoperative switch to extracorporeal circulation; ii) intraoperative massive bleeding and blood perfusion; iii) second surgery within a short time following initial surgery; iv) lengthy postoperative mechanical ventilation support; v) lost to follow-up post-operatively; and vi) death. Thus, 239 patients were enrolled in the present study, 116 and 123 in groups $C$ and D, respectively (Fig. 1).

The results of randomization were sealed in envelopes with serial numbers and placed in the study center under the supervision of the clinical research coordinator (GW). Randomization was performed 30-60 min prior to surgery, which was 30-60 min following the provision of informed consent from the patients. The clinical research coordinator was not blinded to the grouping results. The responsibilities of the clinical research coordinator included assigning the patients to randomized groups, distributing medicine, providing instructions to the anesthesiologists regarding the intraoperative measures, conducting the study protocol under strict guidelines, collecting the data and coordinating the entire study. The anesthesiologists responsible for intraoperative management were blinded to the grouping results. Strict blinding during the follow-up was ensured. In addition, the medical team providing postoperative care in the intensive care unit (ICU) and the wards, the investigators, patients, statisticians, and data and safety oversight committees were all blinded to the grouping results.

Anesthesia management. Identical anesthesia induction with $0.03-0.05 \mathrm{mg} / \mathrm{kg}$ midazolam, $0.15-0.3 \mathrm{mg} / \mathrm{kg}$ etomidate, $0.5-1 \mu \mathrm{g} / \mathrm{kg}$ sufentanil and $0.6 \mathrm{mg} / \mathrm{kg}$ rocuronium was adopted for all the enrolled patients. After anesthesia induction, oral endotracheal intubation (tidal volume, $6-8 \mathrm{ml} / \mathrm{kg}$; respiratory rate, $13 / \mathrm{min}$ ) was performed, and a radial artery puncture for central venous catheter placement or Swan-Ganz catheter placement was performed. The parameters, including the heart rate, mean arterial pressure, oxygen saturation, end-tidal $\mathrm{CO}_{2}$, brain spectral index (BIS), central venous pressure, cardiac output and pulmonary artery pressure were monitored. During anesthesia maintenance, supplementation with identical general anesthetics, analgesics and muscle relaxants was performed, namely propofol and sevoflurane, sufentanil and cis-atracurium. The vasoactive drugs utilized included norepinephrine, nicardipine, milrinone, and esmolol. Following surgery, the patient was transferred to the ICU.

Outcome measures. Venous blood was collected at pre-incision (t1), immediately following sternal closure ( $\mathrm{t} 2)$, then 4,12 and $24 \mathrm{~h}$ postoperatively ( $\mathrm{t} 3, \mathrm{t} 4$ and $\mathrm{t} 5$, respectively). ELISA kits (all, Abcam) were used to detect interleukin (IL)-6 (cat. no. ab46027), tumor necrosis factor- $\alpha$ (cat. no. ab181421), C-reactive protein (CRP; cat. no. ab260058) and IL-10 (cat. no. ab185986) levels. BIS values were recorded a intraoperatively at the $\mathrm{t} 1$ and $\mathrm{t} 2$ time points. Hemodynamic parameters (HR and MAP) at each time point, both intraoperatively and postoperatively were also recorded.

Statistical analysis. The SPSS v21.0 software (IBM Corp.) was used for data analysis. Continuous data are presented as the mean $\pm \mathrm{SD}$ and were analyzed using a t-test. $\mathrm{P}<0.05$ was considered to indicate a statistically significant difference.

\section{Results}

Comparison of clinical data and surgical records. No significant difference in the general condition, complications, cardiac function and surgical records was observed between the two groups (Tables I and II). No significant difference was also detected in the intraoperative doses of the vasoactive drugs between the two groups (Table III).

Comparison of hemodynamic parameters and BIS values at each time point. Patients in the group D had a significantly slower heart rate at $\mathrm{t} 2, \mathrm{t} 3$, and $\mathrm{t} 4$, compared with that in group C (Fig. 2). A significantly lower mean arterial pressure was also observed in patients in group $\mathrm{D}$ at the $\mathrm{t} 2$ and $\mathrm{t} 3$ time points (Fig. 3), while BIS values at $\mathrm{t} 1$ and $\mathrm{t} 2$ in both groups ranged from 40-55 indicating that the depth of anesthesia in both the patients was moderate. However, no significant difference was observed in BIS values between the two groups at these time points (Fig. 4).

Comparison of biochemical indices. Differences were observed in the levels of IL- 6 , TNF- $\alpha$, CRP and IL-10 between the two groups. TNF- $\alpha$ levels were significantly lower in group D compared with that in group $\mathrm{C}$ at the $\mathrm{t} 2$ and $\mathrm{t} 3$ time points (Fig. 5). IL-6 levels were also significantly reduced at the $\mathrm{t} 2$ time point compared with that in group $\mathrm{C}$ (Fig. 6), while the levels of CRP were significantly reduced in group D compared with that in group $\mathrm{C}$, at the $\mathrm{t} 3, \mathrm{t} 4$ and $\mathrm{t} 5$ time points (Fig. 7). Furthermore, the amount of IL-10 in group C was marginally reduced, compared with that on group $\mathrm{D}$, at the $\mathrm{t} 3$, $\mathrm{t} 4$ and $\mathrm{t} 5$ time points; however, this difference was not statistically significant (Fig. 8). 
Table I. Baseline characteristics.

\begin{tabular}{lccr}
\hline & \multicolumn{2}{c}{ Group } & \\
\cline { 2 - 4 } Variable & $\mathrm{C}, \mathrm{n}=116$ & $\mathrm{D}, \mathrm{n}=123$ & P-value \\
\hline Mean age $\pm \mathrm{SD}$, years & $66 \pm 4.5$ & $67 \pm 3.6$ & 0.352 \\
Mean education duration $\pm \mathrm{SD}$, years & $10.6 \pm 3.1$ & $10.6 \pm 3.2$ & 0.961 \\
Sex, female, $\mathrm{n}(\%)$ & $53(47)$ & $56(46)$ & 0.498 \\
Sex, male, $\mathrm{n}(\%)$ & $63(53)$ & $67(54)$ & 0.924 \\
Mean height $\pm \mathrm{SD}, \mathrm{cm}$ & $171 \pm 8.3$ & $170 \pm 8.5$ & 0.723 \\
Mean weight $\pm \mathrm{SD}, \mathrm{kg}$ & $73 \pm 5.2$ & $73 \pm 5.9$ & 0.998 \\
Hypertension, $\mathrm{n}(\%)$ & $103(78)$ & $105(85)$ & 0.721 \\
Diabetes mellitus, $\mathrm{n}(\%)$ & $86(74)$ & $91(74)$ & 0.145 \\
Previous myocardial infarction, $\mathrm{n}(\%)$ & $58(50)$ & $50(41)$ & 0.235 \\
Meanpreoperative $\mathrm{EF} \pm \mathrm{SD}$ & $55 \pm 4.6$ & $54 \pm 5.1$ & 0.535 \\
\hline
\end{tabular}

EF, ejection fraction.

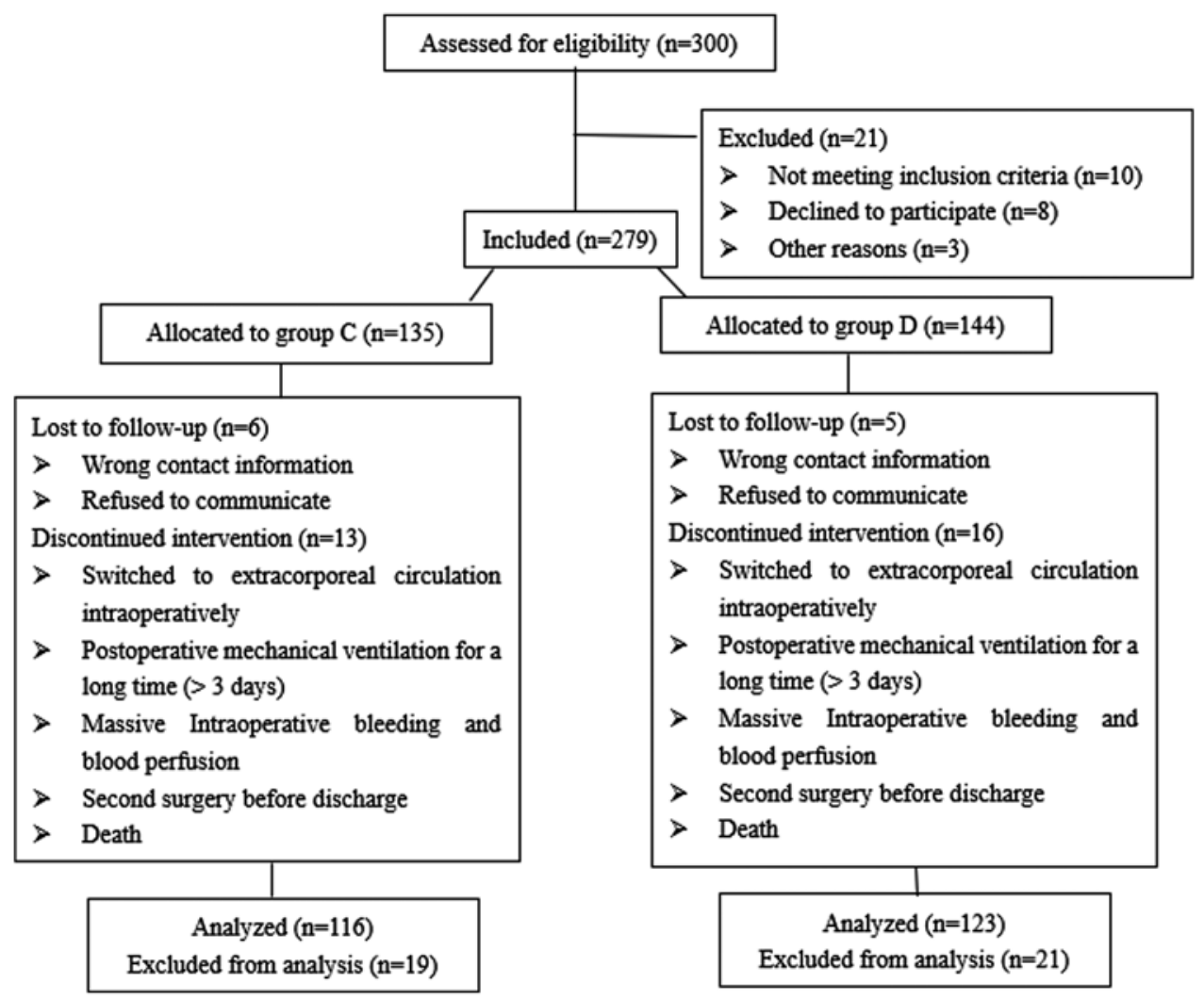

Figure 1. Flow chart of patient enrollment and exclusion.

\section{Discussion}

In the USA, the Food and Drug Administration (FDA) has approved the use of dexmedetomidine for short-term sedation $(24 \mathrm{~h})$ in ICUs for patients undergoing mechanical ventilation and endotracheal intubation. In October 2008, the FDA extended the use of this drug for sedation of non-intubated patients prior to and during surgical and non-surgical procedures (3).

In the present study, the effects of intraoperative use of dexmedetomidine on hemodynamics and inflammatory responses were evaluated during OPCABG surgery. Previous studies have demonstrated the anti-inflammatory effect of dexmedetomidine in clinical practice, yet few have documented this effect in OPCABG (13-16). Furthermore, unlike previous studies $(11,12)$, the clinical trial described in the present study combined clinical indicators and measurement of inflammatory factors to jointly describe the anti-inflammatory effect of dexmedetomidine and its potential clinical benefit.

Dexmedetomidine was found to reduce the mean arterial pressure and heart rate, suggesting a stabilizing effect on 
Table II. Clinical record.

\begin{tabular}{lrrr}
\hline & \multicolumn{2}{c}{ Group } & \\
\cline { 2 - 4 } Variable & $\mathrm{C}, \mathrm{n}=116$ & $\mathrm{D}, \mathrm{n}=123$ & P-value \\
\hline Number of grafts $\pm \mathrm{SD}$ & $3 \pm 0.5$ & $3 \pm 0.6$ & 0.984 \\
Mean duration of anesthesia $\pm \mathrm{SD}, \mathrm{h}$ & $3.8 \pm 0.6$ & $4.1 \pm 0.7$ & 0.845 \\
Mean time spent in ICU $\pm \mathrm{SD}$, days & $2.2 \pm 0.2$ & $2.0 \pm 0.1$ & 0.624 \\
Mean time spent in hospital \pm SD, days & $8.3 \pm 1.2$ & $7.2 \pm 1.3$ & 0.397 \\
\hline
\end{tabular}

ICU, intensive care unit.

Table III. Vasoactive drugs.

\begin{tabular}{lccr}
\hline & \multicolumn{2}{c}{ Group } & \\
\cline { 2 - 4 } Variable & $\mathrm{C}, \mathrm{n}=116$ & $\mathrm{D}, \mathrm{n}=123$ & P-value \\
\hline Premedication & & & 0.922 \\
$\quad$ Dose of $\mu$ orphine $\pm \mathrm{SD}, \mathrm{mg}$ & $5 \pm 0.9$ & $5 \pm 1.0$ & 0.987 \\
$\quad$ Dose of ocopolamine $\pm \mathrm{SD}, \mathrm{mg}$ & $0.3 \pm 0.05$ & $0.3 \pm 0.06$ & 0.367 \\
Positive inotropic drugs & & & 0.201 \\
$\quad$ Mean level of dopamine $\pm \mathrm{SD}, \mathrm{mg} / \mathrm{kg} / \mathrm{min}$ & $3.82 \pm 0.71$ & $4.03 \pm 0.55$ & 0.145 \\
Mean level of milrinone $\pm \mathrm{SD}, \mathrm{mg} / \mathrm{kg} / \mathrm{min}$ & $0.35 \pm 0.02$ & $0.39 \pm 0.03$ & $0.37 \pm 0.06$ \\
Mean level of norepinephrine $\pm \mathrm{SD}, \mu \mathrm{g} / \mathrm{kg} / \mathrm{min}$ & $0.41 \pm 0.06$ & & \\
\hline
\end{tabular}

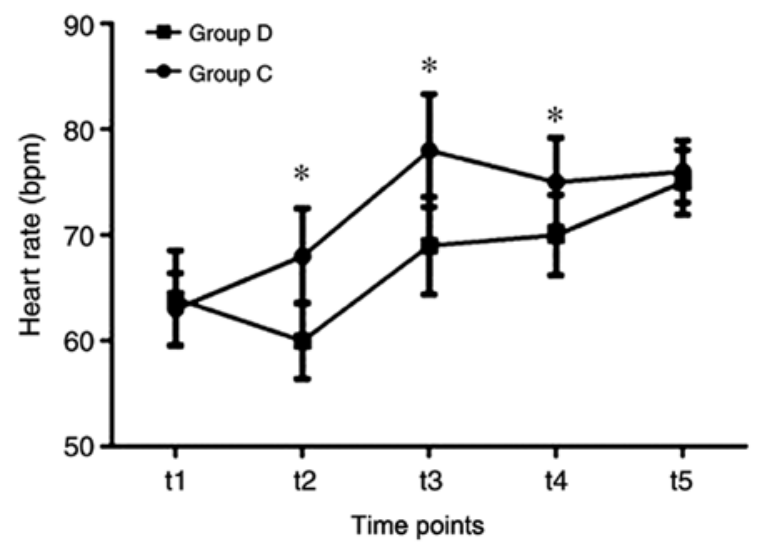

Figure 2. Heart rate in the $\mathrm{D}$ and $\mathrm{C}$ groups. Heart rates were measured at pre-incision (t1), immediately following sternal closure ( $\mathrm{t} 2)$, then 4,12 and $24 \mathrm{~h}$ postoperatively ( $\mathrm{t} 3, \mathrm{t} 4$ and $\mathrm{t} 5$, respectively), and compared between each group at the same time points. Data are presented as the mean \pm SD. ${ }^{*} \mathrm{P}<0.05$ vs. control. $\mathrm{D}$, dexmedetomidine; $\mathrm{C}$, control; $\mathrm{t}$, time.

hemodynamics (17-20). This could be attributed to the ability of dexmedetomidine to reduce sympathetic nerve activity, inhibit the release of sympathetic impulses, and relieve nerve tension primarily according to the highly selective nature of the drug (21). In previous studies, dexmedetomidine did not demonstrate any myocardial inhibition and even exhibited cardioprotection, neuroprotection, and renoprotection by reducing inflammation (22-24). A previous study suggested that the use of dexmedetomidine reduced the requirement for

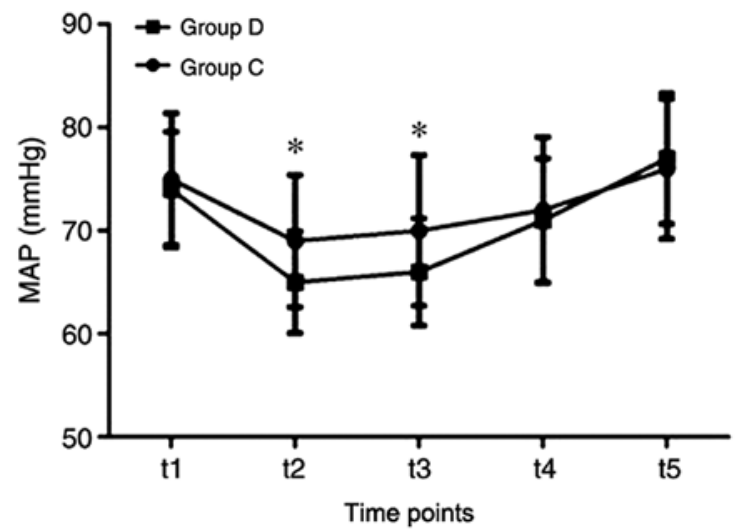

Figure 3. Comparisons of MAP between the two groups at each time point. MAP was measured at pre-incision (t1), immediately following sternal closure (t2), then 4, 12 and $24 \mathrm{~h}$ post-operatively ( $\mathrm{t} 3$, $\mathrm{t} 4$ and $\mathrm{t} 5$, respectively), and compared between each group at the same time points. Data are presented as the mean $\pm \mathrm{SD}$. ${ }^{*} \mathrm{P}<0.05$ vs. control. $\mathrm{D}$, dexmedetomidine; $\mathrm{C}$, control; MAP, mean arterial pressure; $t$, time.

propofol and improved the hemodynamic stability in patients with BIS-guided sedation (25). Consistent with this previous study, the present findings also confirmed that administration of dexmedetomidine did not decrease the BIS values and demonstrated effective stability during anesthetic maintenance at the sedation level.

Trauma and postoperative pain following cardiac surgery contribute to the inflammatory response in patients (26). Inflammatory responses occur intraoperatively, but can 


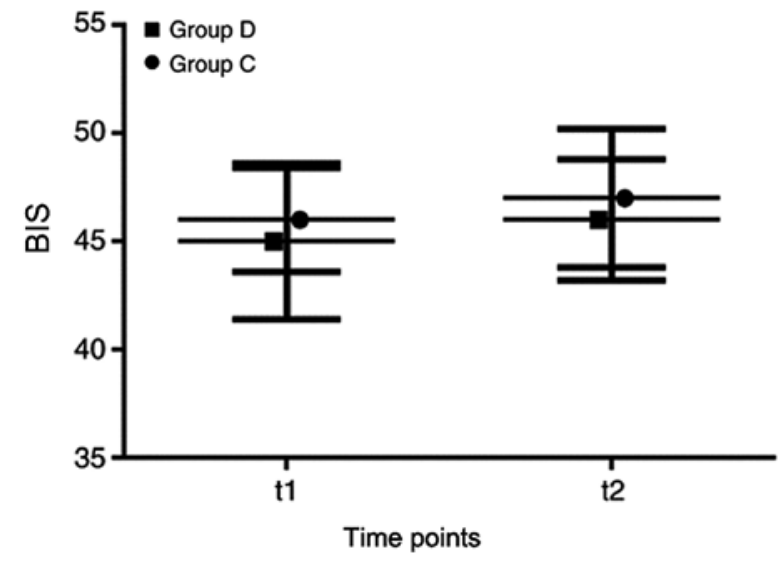

Figure 4. Comparisons of BIS between the two groups at $\mathrm{t} 1$ and $\mathrm{t} 2$ time points. BIS values were measured at pre-incision (t1), immediately following sternal closure (t2), and compared between each group at the same time points. Data are presented as the mean $\pm \mathrm{SD}$. $\mathrm{D}$, dexmedetomidine; $\mathrm{C}$, control; $\mathrm{t}$, time.

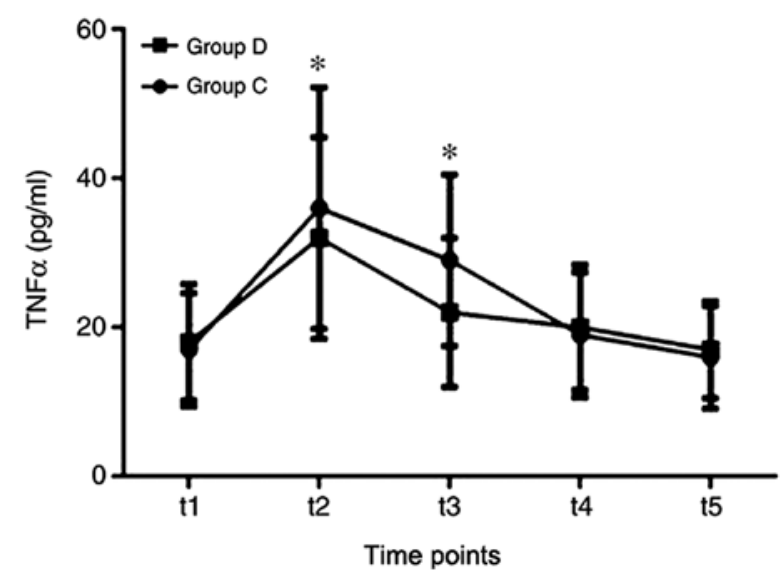

Figure 5. Comparisons of TNF- $\alpha$ between the two groups at each time point TNF- $\alpha$ levels were measured at pre-incision (t1), immediately following sternal closure (t2), then 4,12 and $24 \mathrm{~h}$ postoperatively ( $\mathrm{t} 3$, $\mathrm{t} 4$ and $\mathrm{t} 5$, respectively), and compared between each group at the same time points. Data are presented as the mean $\pm \mathrm{SD}$. " $\mathrm{P}<0.05$ vs. control. $\mathrm{D}$, dexmedetomidine; $\mathrm{C}$, control; TNF- $\alpha$, tumor necrosis factor- $\alpha$; $\mathrm{t}$, time.

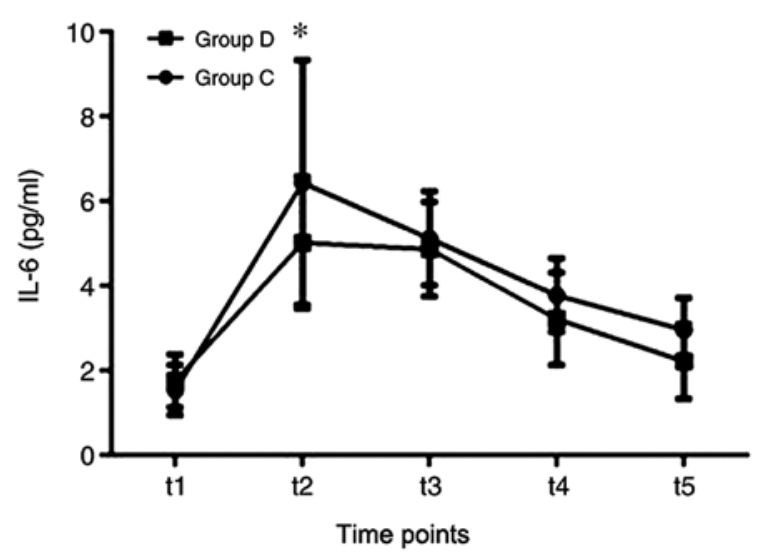

Figure 6. Comparisons of IL-6 between the two groups at each time point. IL-6 levels were measured at pre-incision (t1), immediately following sternal closure ( $\mathrm{t} 2$ ), then 4,12 and $24 \mathrm{~h}$ postoperatively ( $\mathrm{t} 3, \mathrm{t} 4$ and $\mathrm{t} 5$, respectively), and compared between each group at the same time points. Data are presented as the mean $\pm \mathrm{SD} .{ }^{*} \mathrm{P}<0.05$ vs. control. $\mathrm{D}$, dexmedetomidine; $\mathrm{C}$, control; IL, interleukin; $\mathrm{t}$, time.

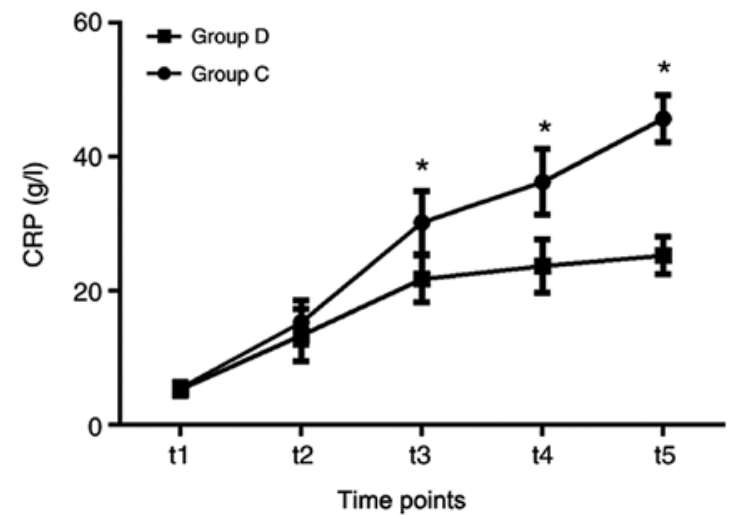

Figure 7. Comparisons of CRP between the two groups at each time point. CRP levels were measured at pre-incision (t1), immediately after sternal closure (t2), then 4,12 and $24 \mathrm{~h}$ postoperatively ( $\mathrm{t} 3, \mathrm{t} 4$ and $\mathrm{t} 5$, respectively), and compared between each group at the same time points. Data are presented as the mean $\pm \mathrm{SD}$. ${ }^{*} \mathrm{P}<0.05$ vs. control. $\mathrm{D}$, dexmedetomidine; $\mathrm{C}$, control; $\mathrm{CRP}, \mathrm{C}$-reactive protein; $\mathrm{t}$, time.

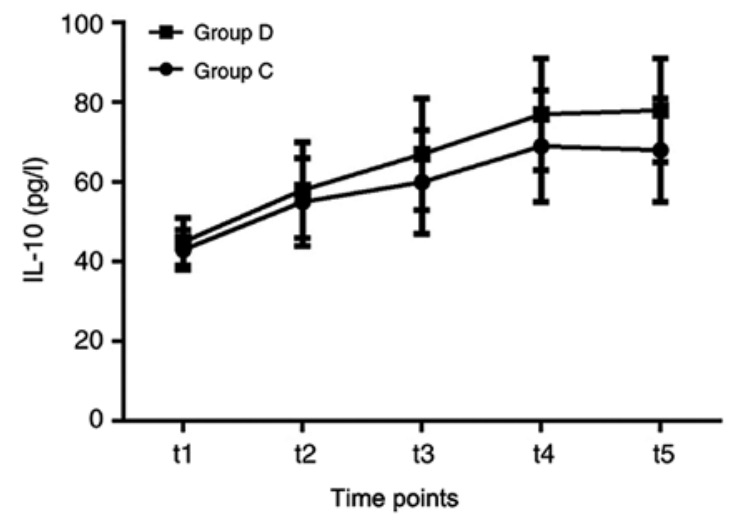

Figure 8. Comparisons of IL-10 between the two groups at each time point. IL-10 levels were measured at pre-incision (t1), immediately after sternal closure ( $\mathrm{t} 2$ ), then 4,12 and $24 \mathrm{~h}$ postoperatively ( $\mathrm{t} 3, \mathrm{t} 4 \mathrm{and} \mathrm{t} 5$, respectively), and compared between each group at the same time points. Data are presented as the mean $\pm \mathrm{SD}$. D, dexmedetomidine; $\mathrm{C}$, control; IL, interleukin; t, time.

also persist postoperatively. Hyperinflammatory responses damage particular organs, including the lung, heart and kidney, and in turn, trigger unfavorable pathological changes, including tissue and cell degeneration, necrosis, changes in hemodynamics (inflammatory hyperemia), increased vascular permeability (inflammatory exudation), fluid exudation and cellular exudation (inflammatory infiltration) resulting in systemic inflammatory response syndrome. This leads to secondary multiple organ injury and dysfunction, affecting postoperative outcomes (including prolonged hospitalization and increased medical costs) and quality of life (27). The postoperative use of dexmedetomidine in patients in ICU effectively inhibits the release of inflammatory mediators, reducing the incidence rate of systemic inflammatory response syndrome (28-31). Dexmedetomidine also significantly suppresses the production of lipopolysaccharide-induced proinflammatory mediators, including TNF- $\alpha$, IL-6, and CRP, both in vivo and in vitro (31-34). IL-10 is an anti-inflammatory cytokine that inhibits the production of IL-6 and TNF- $\alpha$ (35). The present findings also suggested that the use 
of dexmedetomidine during surgery significantly reduced the intraoperative and short-term post-operative levels TNF- $\alpha$ and IL-6. Moreover, dexmedetomidine also reduced the postoperative levels of CRP. Thus, it may be hypothesized that dexmedetomidine activates the central nervous system, as well as the peripheral $\alpha 2$ adrenergic receptor, to reduce sympathetic nerve activity and plasma catecholamine concentration, which then reduces perioperative inflammatory responses $(36,37)$. Indeed, dexmedetomidine has previously been demonstrated to reduce sympathetic tone and indirectly improve parasympathetic tone, which may inhibit systemic inflammatory responses (38). Yang and Hong (39) also suggested that dexmedetomidine could inhibit nuclear factor- $\kappa \mathrm{B}$ activity and activate cholinergic anti-inflammatory pathways. Chen et al (40) investigated whether dexmedetomidine served an anti-inflammatory effect on myocardial ischemia-reperfusion injury in patients who underwent coronary artery bypass graft surgery (CABG) with $\mathrm{CPB}$. The study demonstrated that dexmedetomidine inhibited the increase in cardiac troponin I and creatine kinase isoenzymes, attenuated the production of pro-inflammatory cytokines TNF- $\alpha$, IL-6 and IL-8, and promoted anti-inflammatory cytokine IL-10 production. The results demonstrated that dexmedetomidine regulated the anti-inflammatory response and provided myocardial protection in CABG with CPB (40). Thus, dexmedetomidine could maintain the perioperative hemodynamic stability in patients receiving OPCABG, alleviate the perioperative inflammatory response, and might be beneficial to patients during postoperative recovery.

However, only a single-dose intravenous pump infusion of dexmedetomidine was evaluated in the present study. The study confirmed that dexmedetomidine stabilized hemodynamic parameters in patients undergoing OPCABG surgery; however, the study design could not establish whether the dose used produced an optimal result on coronary indices. Furthermore, follow-up information regarding the short and long-term postoperative outcomes, including the mortality rate and complications, were unavailable. In addition, the use of dexmedetomidine during time spent in the ICU and whether this could also improve patient outcomes was not assessed. The present study also lacked a positive control group, as anti-inflammatory drugs used are not approved for surgery in China, with the exception of ulinastatin. Thus, the findings of the present study should be validated in future studies and the limitations addressed.

In conclusion, anesthesia with dexmedetomidine during OPCABG surgery effectively alleviated stress-induced responses, promoted hemodynamic stability and produced an effective sedative action. Thus, dexmedetomidine may be a potentially suitable anesthetic for clinical use.

\section{Acknowledgements}

Not applicable.

\section{Funding}

This work was supported by the program of ' 131 ' Innovative Talent Team from the Tianjin Talent Working Group of China.

\section{Availability of data and materials}

The datasets used and/or analyzed during the current study are available from the corresponding author on reasonable request.

\section{Authors' contributions}

WZ analyzed the data and wrote the manuscript. LY assisted with cardiac surgery and performed the post-operative follow-up of patients. PS and JH implemented anesthesia and recorded intraoperative data. YL collected patient blood samples and conducted ELISA. GW designed and supervised the trial. All authors read and approved the final manuscript.

\section{Ethics approval and consent to participate}

This study was approved by the Ethics Committee of Tianjin Chest Hospital (approval no. 2012KY-001-01) and was registered at the Chinese Clinical Trial Registry with the trial registration number ChiCTR-OOC-15005978 (2015). All subjects were well informed and provided written informed consent.

\section{Patient consent for publication}

Not applicable.

\section{Competing interests}

The authors declare that they have no competing interests.

\section{References}

1. Malakar AK, Choudhury D, Halder B, Paul P, Uddin A and Chakraborty S: A review on coronary artery disease, its risk factors, and therapeutics. J Cell Physiol 234: 16812-16823, 2019.

2. Nwaejike N, Mansha M, Bonde P and Campalani G: Myocardial revascularization by off pump coronary bypass surgery (OPCABG): A ten year review. Ulster Med J 77: 106-109, 2008.

3. Wang R: Effect of dexmedetomidine continuous infusion on off-pump coronary artery bypass surgery. J Cardiothorac Vasc Anesth 17: 24-26, 2013.

4. Zhang Q, Lu C and Liu G: Effects of dexmedetomidine hydrochloride on postoperative cognitive function in patients undergoing off-pump coronary-artery bypass grafting. Chin J Lab Diagn 16: 346-348, 2012.

5. Weerink MAS, Struys MMRF, Hannivoort LN, Barends CRM, Absalom AR and Colin P: Clinical pharmacokinetics and pharmacodynamics of dexmedetomidine. Clin Pharmacokinet 56: 893-913, 2017.

6. Zhou H, Xiao W and Zhao H: The effect of dexmedetomidine on hemodynamics and stress reaction in patients undergoing cardiac valve replacement surgery. Chin J Exp Surg 28: 2230-2233, 2011.

7. Ling Y, Sun Y and Liang Q: Effects of dexmedetomidine on hemodynamics and stress reaction in pediatric patients undergoing cardiac surgery. Shanghai Medical J 35: 96-100, 2012.

8. Wang $X$ and Chen $\mathrm{H}$ : Effect of remifentanil combined with dexmedetomidine on hemodynamics in the anesthetic of cardiac surgery. Pract Pharm Clin Rem 16: 799-801, 2013.

9. Flanders CA, Rocke AS, Edwardson SA, Baillie JK and Walsh TS: The effect of dexmedetomidine and clonidine on the inflammatory response in critical illness: A systematic review of animal and human studies. Crit Care 23: 402, 2019.

10. Portier K and Ida KK: The ASA physical status classification: What is the evidence for recommending its use in veterinary anesthesia?-A systematic review. Front Vet Sci 5: 204, 2018.

11. Dong W, Chen MH, Yang YH, Zhang X, Huang MJ, Yang XJ and Wang HZ: The effect of dexmedetomidine on expressions of inflammatory factors in patients with radical resection of gastric cancer. Eur Rev Med Pharmacol Sci 21: 3510-3515, 2017. 
12. Zhang $Y$, Jia S, Gao $T$, Zhang R, Liu Z and Wang $Y$ : Dexmedetomidine mitigate acute lung injury by inhibiting IL-17-induced inflammatory reaction. Immunobiology 223: 32-37, 2018.

13. Gallego-LigoritL,VivesM,Vallés-TorresJ,Sanjuán-VillarrealTA, Pajares A and Iglesias M: Use of dexmedetomidine in cardiothoracic and vascular anesthesia. J Cardiothorac Vasc Anesth 32: 1426-1438, 2018.

14. Rong H, Zhao Z, Feng J, Lei Y, Wu H, Sun R, Zhang Z, Hou B, Zhang W, Sun Y, et al: The effects of dexmedetomidine pretreatment on the pro- and anti-inflammation systems after spinal cord injury in rats. Brain Behav Immun 64: 195- 207, 2017.

15. Li $\mathrm{H}$, Zhang $X$, Chen $M$, Chen $J$, Gao $\mathrm{T}$ and Yao $\mathrm{S}$ : Dexmedetomidine inhibits inflammation in microglia cells under stimulation of LPS and ATP by c-Fos/NLRP3/caspase-1 cascades. EXCLI J 17: 302-311, 2018.

16. Cheng M, Gao T, Xi F, Cao C, Chen Y, Zhao C, Li Q and Yu W: Dexmedetomidine ameliorates muscle wasting and attenuates the alteration of hypothalamic neuropeptides and inflammation in endotoxemic rats. PLoS One 12: e0174894, 2017.

17. Ihmsen H and Saari TI: Dexmedetomidine. Pharmacokinetics and pharmacodynamics. Anaesthesist 61: 1059-1066, 2012 (In German).

18. Mo W, Li B and Tan W: Effect of dexmdetomidine on hemodynamics during induction of anesthesia in cardiac surgery. Chin J Misdiagn 11: 1604-1605, 2011.

19. Jiao F, Chen H and Huang C: Effects of dexmedetomidine on hemodynamics and stress response in the perioperative period of infant cardiac surgery. Modern Hospital 14: 45-47, 2014.

20. Xue Z, Wang S and Liu A: Effects of dexmedetomidine on hemodynamics during induction of anesthesia in patients with atrial fibrillation with rapid ventricular rate undergoing noncardiac surgery. Chinese J Anesthesiol 34: 1452-1454, 2014.

21. Kawazoe Y, Miyamoto K, Morimoto T, Yamamoto T, Fuke A, Hashimoto A, Koami H, Beppu S, Katayama Y, Itoh M, et al: Effect of dexmedetomidine on mortality and ventilator-free days in patients requiring mechanical ventilation with sepsis: A randomized clinical trial. JAMA 317: 1321-1328, 2017.

22. Mato M, Pérez A, Otero J and Torres LM: Dexmedetomidine, a promising drug. Rev Esp Anestesiol Reanim 49: 407-420, 2002 (In Spanish).

23. Afonso J and Reis F: Dexmedetomidine: Current role in anesthesia and intensive care. Rev Bras Anestesiol 62: 118-133, 2012.

24. Arcangeli A, D'Alo C and Gaspari R: Dexmedetomidine use in general anaesthesia. Curr Drug Targets 10: 687-695, 2009.

25. Triltsch AE, Welte M, von Homeyer P, Grosse J, Genähr A, Moshirzadeh M, Sidiropoulos A, Konertz W, Kox WJ and Spies CD: Bispectral index-guided sedation with dexmedetomidine in intensive care: A prospective, randomized, double blind, placebo-controlled phase II study. Crit Care Med 30: 1007-1014, 2002.

26. Sommer C, Leinders $M$ and Üçeyler N: Inflammation in the pathophysiology of neuropathic pain. Pain 159: 595-602, 2018

27. Marshall JC: SIRS and MODS: What is their relevance to the science and practice of intensive care? Shock 14: 586-589, 2000.
28. Deng Y, Tan F, Gan X, Li X, Ge M, Gong C, Hei Z, Zhu Q and Zhou S: Perioperative application of dexmedetomidine for postoperative systemic inflammatory response syndrome in patients undergoing percutaneous nephrolithotomy lithotripsy: Results of a randomised controlled trial. BMJ Open 8: e019008, 2018.

29. Seyrek M, Binbay M, Yuruk E, Akman T, Aslan R, Yazici O, Berberoglu Y and Muslumanoglu AY: Perioperative prophylaxis for percutaneous nephrolithotomy: Randomized study concerning the drug and dosage. J Endourol 26: 1431-1436, 2012.

30. Ueki M, Kawasaki T, Habe K, Hamada K, Kawasaki C and Sata T: The effects of dexmedetomidine on inflammatory mediators after cardiopulmonary bypass. Anaesthesia 69: 693-700, 2014.

31. Li B, Li Y, Tian S, Wang H, Wu H, Zhang A and Gao C: Anti-inflammatory effects of perioperative dexmedetomidine administered as an adjunct to general anesthesia: A Meta-analysis. Sci Rep 5: 12342, 2015.

32. Sukegawa S, Higuchi $H$, Inoue $M$, Nagatsuka $H$, Maeda $S$ and Miyawaki T: Locally injected dexmedetomidine inhibits carrageenin-induced inflammatory responses in the injected region. Anesth Analg 118: 473-480, 2014.

33. Taniguchi T, Kidani Y, Kanakura H, Takemoto $\mathrm{Y}$ and Yamamoto K: Effects of dexmedetomidine on mortality rate and inflammatory responses to endotoxin-induced shock in rats. Crit Care Med 32: 1322-1326, 2004.

34. Kawasaki T, Kawasaki C, Ueki M, Hamada K, Habe K and Sata T: Dexmedetomidine suppresses proinflammatory mediator production in human whole blood in vitro. J Trauma Acute Care Surg 74: 1370-1375, 2013

35. Yuan X: Effect of laparoscopic radical resection of colorectal cancer on serum CRP, IL-6 and IL-10 expression. J Pract Clin Med 18: 47-48, 2014

36. Xu F, Yang CX and Deng SZ: Progress of clinical application of dexmedetomidine in perioperative period. Int J Anesthesiol Resuscit 32: 336-340, 2011.

37. Tanskanen PE, Kyttä JV, Randell TT and Aantaa RE: Dexmedetomidineas an anesthetic adjuvant in patients undergoing intracranialtumor surgery: A double-blind, randomized and placebo-controlled study. Br J Anaesth 97: 658-665, 2006.

38. Geng F, Yu L and Long D: The effect of dexmedetomidine on postoperative cognitive function and inflammatory response of elderly patients undergoing laparoscopic radical gastrectomy. J Prev Med PLA 5: 146-147, 149, 2019.

39. Yang D and Hong JH: Dexmedetomidine modulateshistamine-induced $\mathrm{Ca}^{2+}$ signaling and pro-inflammatorycytokine expression. Korean J Physiol Pharmacol 19: 413-420, 2015.

40. Chen S, Hua F, Lu J, Jiang Y, Tang Y, Tao L, Zou B and Wu Q: Effect of dexmedetomidine on myocardial ischemia-reperfusion injury. Int J Clin Exp Med 8: 21166-21172, 2015.

This work is licensed under a Creative Commons Attribution-NonCommercial-NoDerivatives 4.0 International (CC BY-NC-ND 4.0) License. 